\title{
Review of Research on Deliberate Practice and Oral English Learning of University in Mainland China
}

\author{
Lulu Wang
}

Guangdong University of Foreign Study

Wll13528450898@126.com

\begin{abstract}
Background and Purpose - Based on English teaching situation and reform requirement, the purpose of this paper is to explore how Deliberate Practice applies to Oral English learning through reviewing English-language and Chineselanguage publications about Deliberate Practice and oral English learning in university in China published mainly between 2000 and 2021 and to present an overview of the authorship, topics, methodologies and key findings of these publications.

Design/methodology/approach - The methodology includes an exhaustive review of journal articles and book chapters about Deliberate Practice and oral English learning published in the English language and the Chinese language. In total, 27 articles and two book chapters are identified mainly for the 2000-2021 period.

Findings - The paper identifies several connections among DP, oral English learning and debate. The results show that students in higher education lack critical thinking, debate is a advantageous way of cultivating critical thinking in oral English training and DP enable students to gain meta-cognition ability in oral English practice.
\end{abstract}

Keywords: China, oral English, Deliberate Practice, debate

\section{INTRODUCTION}

In our age of current globalization, oral English learning becomes increasingly important in China due to its opening up to the world. Economically, China builds more stable cooperation with the international world and transnational corporations are booming, in which English, especially spoken English, holds an essential role. Educationally, with the further development of economy and level of life, parents and students pay more attention to international education $(\mathrm{Hu}, 2003)$ [21]. For students who apply for international study programs in Englishspeaking countries, one of key requirements is their English language proficiency. Long after admission, however, language proficiency proceeds to play an critical role in international students' academic acculturation (Sawir et al., 2012)[42], because they need to interact with others in academic and non-academic settings. Among the four skills of language proficiency, speaking is particularly cardinal, for the reason that it affects international students' ability to engage academically and socially.
In China, however, the oral component of English language learning is not perceived as important as reading, writing, and listening (Xing \& Bolden, 2019)[8] for a long time until in 2001, Chinese government promulgated a new round of curriculum reform of which the status of oral English was set on a higher level. That is because scholars have discerned that under traditional teaching system, the teaching situation where teachers solely transmit textual knowledge such as grammar, vocabulary and solely emphasize the requirements of what exams include, for instance, reading and writing, has led to many negative results, such as the phenomenon of being able to read and write, but not to speak. Education thus becomes an act of depositing, in which the students are the depositories and the teacher is the depositor (Freire, 1970)[34]. Meanwhile, they realize more clearly that the essence of reaping English skill is that one enables to express his/her ideas and thoughts and being able to speak is one of the influential indicators of mastering the language. Therefore, under the new round of curriculum reform, more educators are attempting to improve or replace traditional modes of teaching with more proper ones fitting Chinese context, for instance, 
communicative approach. However, the outcomes are still not significant. The situation of difficulty in boosting motivation and inactive participation remains.

Currently, at home and abroad, a new training modelDeliberate Practice (DP) has been studied and applied in the training and shaping of pilots, teachers, surgeons and musicians because evidence showed that this practicebased, targeted and purposeful approach has achieved positive results. Through Liu's quantitative research of developing French pronunciation based on DP (2020)[40], it has been proved that French pronunciation of $76.92 \%$ participants (13) participants in total) was improved in terms of two standards, speaking tongue twister and vocabulary.

Besides DP, the training based on the Social-cultural Theory (SCT) is widely developed because research found that learning should be construed as taking place in various contexts. Context is no longer taken as a backdrop for explaining individual variations, but viewed as shaping all aspect of learning such as learners' strategy use. Under this theory, debate is suggested to be used in English speaking teaching because research suggested that this simulation training can spur communicative skills, such as critical thinking and knowledge enrichment of subject being discussed.

However, in Chinese education context, DP and debate mainly separately used in economics, psychology, social work, technology, sociology, biotechnology, environmental management, international business, nursing, marketing and science, and they are rarely used in language learning together, especially oral English learning.

Within situation that application of DP to oral English teaching and learning is limited and within situation that teaching and learning of English speaking encounters urgent updating under finite improvement, this study aims to cover this gap by exploring the connection between DP, debate and oral English studying, which is important for further study in this field.

This paper attempts to apply the idea of DP and debate on the teaching and learning process of English speaking skill. Given that the aim is about application, the review focuses purposefully on the practical relationship so as to answer the following questions:

1. What is the weakness of oral English in Chinese higher education?

2. What is the impact of cultivating thinking ability in the training of oral English?

3. What advantages does debate have in learning?

4. what ability can students procure in class applying DP?

\section{LITERATURE REVIEW OF DP}

This chapter will touch upon the DP. It is to start from reviewing DP's definition to another three key concepts regarding long-term working memory, implicit knowledge as well as contextual learning.

\subsection{Deliberate Practice}

DP propounded by the psychologist Ericsson and his colleagues is a theory of developing one certain skill, which explains growing process of extraordinary experts in various fields. This theory directly makes contradictions against the theory of gene-decision of Galton which strongly backs that the talented aptitude of genius is given by birth, by gene (Galton, 1872)[14]. Distinctive from Galton theory in total, DP believes that genius in any field is from training that is appropriately organized and from strict practice. Due to its advancement and flexibility, many researchers have done a multitude of reasoning on it and have advocated application of deliberate training practice in many academic areas.

When standing on different sides, scholars make separate definitions to DP. From the perspective of its purpose, DP is a repeated activity that requires keeping consistent conduction with consciousness, purposes and plans to improve certain skill (Guan et al., 2015)[36]. In this version of definition, Guan emphasizes the aim/result that learners are able to reap through conducting DP, which, to some extents, gives learners some expectations. On the side of principals, DP is a purposeful practice which has unambiguous aim, is concentrated, includes feedback and requires "Zone of Proximal Development" (Vygotsky, 1978)[44]. At this level, the advocates majorly put their stresses on some principals or commands of DP, which shows us how to apply DP (Liu, 2020)[40]. From depiction of changes in mental made through DP, DP is able to render learners construct specialized cognitive representation through practice to make changes in cognition and then render implicit knowledge explicit so that participants ascend their ability to recognize internal rules of things and ability to resolve problems and so become experts in their academic fields (Xie et al., 2020)[12]. Seeing from the evolution of this theory, at the beginning, DP was defined as an activity which was most efficient to develop academic performance (Ericsson et al., 1993)[14]. After evolution of twenty years, its content has been enriched. Currently, DP is perceived as conduction-required training activity which lasts for long time and more specifically, as activity that is designed meticulously to develop personal performance, which renders learners continuously break their upper limit to procure lasting improvement (Bronkhorst et al., 2014)[6]. Standing on the facet of essence, DP is an activity full of subjective efforts to ascend self-ability, which aims to construct mental representation and then formulate long- 
term working memory (Sauer et al., 2018)[41]. Lastly, taking participants in practice into consideration, DP is a special training activity that is followed with consciousness, purpose and plan and that is designed by teachers, guiders, couch or individual who have been expert in their areas, which plays the essential role in individual achievements (Ericsson, 2014)[11].

Viewed from different sides, the emphasis of DP is various. Language learning needs effective environment to exercise internal logic behind grammar and expressions, which is associated with long-term working memory, implicit knowledge and contextual learning.

\subsection{Long-Term Working Memory}

Ericsson and Pool (2016)[1] expounded that longterm working memory is a cardinal ability to identify normal people and extraordinary people and is the essence of DP. Those people regarded as experts, they can relate working memory with long-term memory and can take advantages of the working memory when performing academic activities. Knowledge hided behind long-term working memory is implicit knowledge. That is to say, what knowledge that DP focus on is implicit knowledge. It appears that what we are training in practice is not explicit knowledge, but implicit knowledge that is essential method concerning our cognition behind superficial knowledge.

\subsection{Contextual Learning}

For cultivation of implicit knowledge, Ericsson and Pool's thought (2016)[1] is that implicit knowledge is held in contextual learning. He believes that people's "bounded rationality" demonstrated in learning is "contextual rationality" - where we use is where we learn. Meanwhile, it has been proved from a host of learning scientific studies that the most appropriate mode of learning for adults is not individual learning, but contextual learning. Effective learning is to enter related context which encompasses "learning community". Initially, learners do some edged work following with key members. Then with ascending of their ability, they gradually come in essence of community to be in charge of more important business and finally, they become experts.

This chapter refers to definitions of DP, long-term working memory, implicit knowledge and contextual learning. During learning oral English, contextual learning can offer an effective environment where learners can absorb implicit knowledge through longterm working memory. In next chapter, oral English learning will be focused.

\section{ORAL ENGLISH LEARNING}

For oral English learning in university, there are some methods. This chapter is going to introduce definition of learning and oral English learning, and debate as one new instance of teaching methods.

Definitions of learning are varied according to various links between context and cognition. Under the belief that context and cognition is separate entirely, which is different from the idea that stress the combination of context and cognition, the behaviorism considers that learning is defined as the process of continuous reinforcements reacting to stimulus (Feldman, 2004)[39]. The advocates of this learning definition hold the philosophical belief that free will is illusion and our human beings are shaped entirely by their external environment. Different from behaviorism, the Theory of Second Language Acquisition "view learning as a social accomplishment, having social histories, and being only possible through sociality" (Ortega, 2011, p. 168)[33]. In the socially-oriented theory, context is no longer regarded as background to explain the differences among students, but thought to be one of teaching and learning strategies. Therefore, the link between context and cognition is interrelated.

Influenced by behaviorism and socially-oriented theories, definitions to oral English learning also is diversified In behaviorism's eyes, language learning is also one form of behavior. It can be learned the same way as an animal is trained to respond to stimuli, such as classical conditioning and operant conditioning. In contrast, socially-oriented theories believe that oral English learning is best achieved through the dynamic interaction between the teacher and the learner and between learners (Vygotsky, 1978)[44], which highlights the significance of social interactions and the role of culture in creating knowledge. With the teacher's careful scaffolding through questions and explanations or with a more capable peer's support, the learners can move to a higher level of understanding and extend their skills and knowledge to the fullest potential.

Having discussed about definitions of learning and oral English learning between different theories, it comes to teaching methods in oral English learning. Traditionally, one of ways to teach oral English learning begins from grammar. Under grammar-translation methods, students reap the ability of oral English through explanations of individual points of grammar and some sentences which can exemplify the rules, where students are passive to receive learning. To some extent, this way enables students to know what standard sentences are, but largely it prohibits students creativity and motivation. For instance, a teacher asks "how are you?", and students always reply "I am fine, thank you! And you?" rather than other responses. Though this dialogue is fit for the rule of grammar, the structure of sentences is limited. Within this condition, students are only able to speak English in such question with fixed structure but not able to respond in more flexible ways. Therefore, when they encounter a greeting that "how is thing going?" in real life, they are struggled to react to it. 
Different from traditional one, the SCT maintains that human cognition is socially-mediated in that such higherorder mental functions as attention, planning, and problem-solving take place through social activities (Lantolf, 2006; Lantolf, 2000a)[26][27]. On the premise of this, oral English development generates from meaning-constructing in social interactions. Within SCT, social mediation is the core. It combines context and cognition. Mediation originates from artifacts, other people, and the self (Lantolf, 2000b; Vygotsky, 1978)[28][44]. The concept of mediation was further developed into Activity Theory. This Theory expounds that specific goal-oriented actions, mediated by suitable approaches, scaffold individuals to fulfill their motives under particular spatial and temporal conditions (Lantolf, 2000c)[29]. Under the Activity Theory, oral English learning can be framed as an activity where learners are subjects in participation, the progress of their oral English proficiency is perceived as object, and the whole learning process is mediated by artifacts, rules, roles, and community as embodied in sociocultural resources.

Above all, it talks about the theory of learning and oral English learning, and next debate, as one of specific teaching modes, will be elaborated as an example. Under the perspective of SCT theory, oral English is organized when learners attend in practice activities, such as, public speaking, debate. English debate is a new mode of learning English existing in 1990s and is respected and spread widely by educators in China due to its efficiency in teaching and popularity among students (Li, 2020)[30].

Debate is a formal learning approach of interactive and representational argument aimed at persuading audience, which can be used to teach speaking in the EFL classes (Fauzan, 2016)[13]. Through debate can we reap learning of critical thinking, communication skill, indepth knowledge associated with subject, and increase motivation to learn more (D'Souza, 2013)[9], for instance, learners are encouraged to discover various facets rather than only one extreme side on opinion of one stuff, which is one of characteristics that critical thinking includes. Students also learn more through debates than through lectures (Combs \& Bourne 1994)[7]. Of those, critical thinking in English mode and communication skills are one of the keys for oral English training. English-like Critical Thinking means conveyance of independent and analytical messages like speakers' in target language in the process of interaction, while communication skill, such as interpersonal, phatic skills and proficiency in public speaking coincides with communication. It can be seen that debate is beneficial to the teaching of oral English in class because critical thinking compasses the thinking pattern of a language and communication is one of purposes of any language.

Before preparation of debate, a suitable motion will be chosen by teachers based on observation to the current attainment of students. Instructed by this motion, students begin to look for materials that are strong enough to support their arguments, during which teachers play roles of guiders, facilitators, and managers to help them go on smoothly. Then, after accumulating sufficient evidence, students will be given rich time to do rehearsal in pairs and write an outline of their arguments in order to reach the aims of both output of oral English and preparation of debate. Finally, debate takes place in class. Overall, within the whole session, students are able to learn lexis and knowledge associated with topic that is taught in class and pronunciation and making arguments in English ways.

In terms of a variety of research done by scholars, it has been evident that debate, as a strategy of teaching and learning oral English, is effective and advantageous. Standing on the side of students, their fluency is improved. Then, through preparation of debate, they reap more motivation of self-learning and oral English learning. They need to be responsible for understanding the assigned topic through detailed studies and evaluation of competing choices. In D' Souza's study (2013)[7], it proves a very strong relationship between debate and interest motivation of subject. Meanwhile, due to enough rehearsal and suitable motion, excellent performances build up their confidence to speak out bravely in English.

Standing on the side of teachers, it is rewarding for them to implement debate as a teaching method used in class for the reason that they will be satisfied to see the progress that the students make in every debate, which to some extent, increases the well-being of teachers. That is because they are able to feel self-accomplishment while seeing the progress that their students make under the guidance from them (Li, 2021)[31]. Furthermore, with acquisition of self-achievement in work, teachers deepen their satisfaction to the job (Barbieri et al., 2019)[5]. Besides, it also increases the efficacy of teaching (Acheson et al., 2016)[3] as students are active to learn oral English. In debate class, the roles of teachers are guides and facilitators, while the role of students is explorers, which demonstrates the agency of students and students-centered class. In this case, with full motivation of interest, the effectiveness of teaching is surging.

Aside from benefits that the students and teachers can get, for the whole class, debate also boost positive atmosphere in class as learning takes place in students themselves and between students. That is to say that the whole class takes students as center and students are able to practice oral English out of their own creativity, which is also an outcome of learning. Also, in teamwork, they can listen to different perspectives from others and formulate a big picture of the entire issue that they are discussing, which promotes learning ambience in the whole class.

Apart from those benefits, limitations still exist. The whole conduction of debate is based on the topic. In other words, topic's choosing is important for debate. However, 
some topics cannot demonstrate the whole content that students are required to master. Besides, debate is controversial so that for some students who are favor of positive side, but are arranged to stand on the negative side, it might lead to their frustration and anxiety (Moeller, 1985)[32]. Furthermore, debate is not suitable for all courses, because the arguments in some courses are clearcut and purely based on fact. Standing of the angle of students, limitations of debate also take place. For some students from certain cultures, they might be not willful to take part in debate, since it is confrontational in feature. Also, it is not equal for those who are shy and introverted to convey their thoughts in public. In addition, the expectations of what teaching technique students want teachers to use are diversified. For example, some are fond of lecture mode. Therefore, it probably affects the receptivity to debate.

DP not only emphasizes the importance of contextual learning, but also expounds stages of self-learning, which seemingly can cover some gaps in debate training. In this way, it is likely to connect advantages of DP with that of debate to wax efficiency of learning oral English and wince limitations of only using DP or debate. In this level, they perhaps have commons among these definitions. Conceptual framework is as followed.

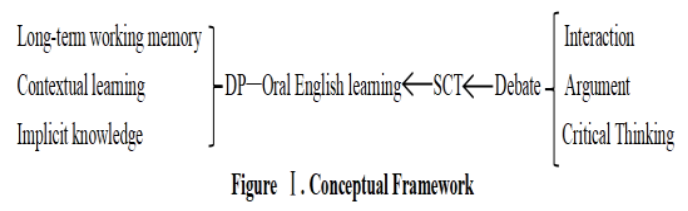

\section{METHODOLOGY}

I reviewed the literature about DP, debate, and oral English learning in the background of Chinese university. This section outlined why I chose to do qualitative research by using secondary data, how I identified the sources for the review and what problems and limitations were in reviewing.

\subsection{Epistemological Position}

Kuhn (1970)[43] expounds that "Paradigm" is a recognized scientific achievement, and it provides a series of solutions for members of a scientific community in a certain historical period. The worldview refers to people's fundamental views to the world where they live and the relationship between people and the world (Sheng, 2009)[18]. The reason why I need to refer to these two things at the beginning of methodology is that the worldview instructs my understanding of oral English learning, and methods' usage of it, which may explain the scope and angle of my research, while the paradigm could direct the general and specific approach of the whole study, which is impacted by what my worldview is.

Worldview is associated with ontology, axiology, and epistemology, based on which I expounded my idea of the paper and designed the methodology in accordance with the research questions. The ontology is in terms of the current situation that in Chinese universities, students feel hard to develop their oral skill in English. Under this background, my value is that having an excellent ability of oral English is important. That is because in my belief, the essence of a language is that people are able to effectively express their ideas orally. Faced with the reality and my thought, therefore, I want to explore a learning method of oral English in an efficacy way. In terms of my previous experience that I have taken part in some English debates where I thought that I got progress on my speaking skill, and that I have read the book Deliberate Practice, where the author explains several principals about skill acquisition, I considered whether these two things could be combined to improve oral English. In this way, the epistemology is inclined to be the theory of constructivism that emphasizes inductive logic to figure out the links among DP, debate and oral English learning. Therefore, the methodology of my paper is qualitative method approach.

\subsection{Research Method}

There were two main reasons why I decided to do qualitative research by using secondary data on the topic of DP, debate and oral English learning. First, I found that few scholars linked DP and debate with oral English learning in research when I was investigating the background information concerning this field. In this case, I wanted to learn the relationship among them basically through theoretical research. Second, there seemed to be hardly no one to do empirical study of applying DP to the oral English learning from my investigation. Therefore, it was an opportunity for me to do preparation before I started conducting my empirical experiment about DP and oral English.

\subsection{Sampling Strategy}

I included journal articles and book chapters, parts of which were originated from China and parts of which came from other countries such as the UK and Indonesia. I made this decision for two reasons. First, the theory of DP was founded by foreign scholars. Thus international research and data were likely to be diversified and abundant. Second, since the aim of this paper was to learn oral English learning in Chinese university, domestic research was probably suitable to the situation in China.

\subsection{Data Collection}

My target databases for candidate sources included China National Knowledge Infrastructure (CNKI) and website of SCOPUS. I input several different combinations of keywords to search for appropriate pieces. These key phrases could be classified into three 
aspects. First was about DP. In this aspect, I input "Deliberate Practice", "Deliberate Practice and cognition", as well as "Deliberate Practice and metacognition". Second was about oral English. In this part, the key words contained "Oral English learning", "Oral English learning in China", "Oral English learning in Chinese university", and "Current flaws in Chinese oral English learning". Third was regarding debate. In this facet, I input "Debate", "Debate and thinking", "critical thinking in debate training", and "Debate training in Chinese university".

By using the word of "Deliberate Practice", the results mostly showed literature about the field of Anesthesiologists, nurses and pioneers, which had no link to my research question. Therefore, I narrowed down the key word to "Deliberate Practice and cognition" and "Deliberate Practice and meta-cognition". In this case, the results demonstrated articles that were helpful to solution of my questions. Besides, by inputting "Oral English learning", there were also multitudes of results non associated with the objective to collect data about current situation of learning oral English in Chinese university. In this way, I extracted those literature about judging and comments for oral English. Since influenced by this searching experience, later, when I was figuring out the debate training in Chinese university, I attempted to add some determiners in the search terms, such as "Debate and critical thinking in university". In this process, I have got eight pieces of papers.

Apart from retrieving key words directly, I also followed a "snowball strategy" by scanning the reference lists of relevant pieces to identify other suitable articles or chapters. With this strategy, the papers that I reviewed were inclined to be in accord with the theme of my research questions. Therefore, through this strategy, the number of my collected papers was up from eight to 27 .

Any piece that fitted our search criteria was downloaded in its entirety. These downloaded articles comprised the full corpus of literature I intended to analyse. The search identified 27 journal papers and two chapters of one book, which would be displayed chronologically in the first table. The second table showed one example of how I arranged the papers involved.

\begin{tabular}{|c|c|c|c|c|c|}
\hline Type & $<2000$ & 2000-2007 & 2008-2016 & 2017-2021 & Total \\
\hline Article & 2 & 5 & 6 & 14 & 27 \\
\hline $\begin{array}{l}\text { Chapters } \\
\text { (Book) }\end{array}$ & 0 & 0 & 2 & 0 & 2 \\
\hline Total & 2 & 5 & 8 & 14 & 29 \\
\hline
\end{tabular}

\begin{tabular}{|c|c|}
\hline Journal & JOURNAL OF GUANGDONG UNIVERSITY OF FOREIGN STUDIES \\
\hline $\begin{array}{c}\text { Author(s) } \\
\text { year }\end{array}$ & Zhang Yi Qiong (2010) \\
\hline $\begin{array}{l}\text { Title of } \\
\text { paper }\end{array}$ & $\begin{array}{l}\text { English Debate and Cultivation of Students' Thinking Ability in } \\
\text { English Major -Taking English debate rules as the guiding ideology }\end{array}$ \\
\hline $\begin{array}{l}\text { Research } \\
\text { question }\end{array}$ & $\begin{array}{l}\text { whether English Debate training is effective in cultivating thinking } \\
\text { ability of university students with English major }\end{array}$ \\
\hline $\begin{array}{l}\text { Research } \\
\text { topic }\end{array}$ & English debate training and thinking ability in English major \\
\hline Methodology & interview \\
\hline Findings & $\begin{array}{l}\text { Students generally reflect that their logical thinking and critical } \\
\text { thinking ability have been improved in the subjective evaluation of teaching } \\
\text { evaluation, which makes them have a sense of accomplishment in their English } \\
\text { learning. }\end{array}$ \\
\hline
\end{tabular}

Table II. Part of the spread sheet including the coded data

\subsection{Methodological Issues and Limitations}

During reviewing, it was hard to do fully smoothly. In my paper, there was one problem as which I had attempted to have it resolved. Since some literature that I review was written in Chinese, I needed to translate them from Chinese to English, during which potential problems existed. Due to translation, I might be not able to convey the full meaning that the original authors want to express or to use appropriate English expressions to describe the Chinese text. In this case, translation became main focus that I encountered in my reviewing. Therefore, I found two specialists in language working in Guang Dong University of Foreign Language, one was expert at written translation, the other one was expert at linguistics. After receiving their suggestions of revision, I revised my translation twice time and then got acceptance from their both agreements.

During collection of data, it still had two limitations. First, the number of literature that I reviewed was not very sufficient. In China, currently, study of applying DP on oral English learning was few. Collocation of data about this field was limited, which might lead to a situation that I probably gave some subjective statements. Second, since my research was mainly based on China, the journals that were written by Chinese authors accounted for a large part. It did not refer to a variety of countries and regions. Therefore, the source of data was not exceedingly diversified. Besides, limited by style of this paper, review paper, it lacked strong support of experiments that could display quantitative analysis. In this case, empirical study was necessary in the future.

\section{FINDINGS AND DISCUSSIONS}

\subsection{What is the weakness of oral English in Chinese higher education?}

On the layer of cognitive skill, Sun (2015)[49] expounds that "thinking ability means depiction, 
explanation, analysis, judgment, and deduction to concept, method, standard, evidence and background" (p.23). Under the background of Chinese higher education, the findings show that oral English teaching seems to lack the training of thinking skill (Shi, 2017; Wen, 1999; Zhu, 2021)[22][35][46], which may lead to a negative phenomenon that English majors are not able to produce thinking conveyance very well.

In China, teaching of English major has not been stressing cultivation of thinking skill. In plan of teaching, objective is mainly to satisfy the requirement of ascending English level and satisfy the cultivation of four skills (listening, speaking, reading, writing), among which the development of students' thinking skill is ignored.

(Wen, 1999) [35]

From this saying, it appears that teachers in university majorly pay attention to correctness and fluency of speaking. With these standard, "grammar and pace" (Shi, 2017, p.69)[22] become the cores in lesson and in assignments. In class, teachers mainly care mistakes of speaking when students are answering questions or giving perspectives. In judgement of assignments, for example, recording, grammatical correctness and speed are the two major criteria in grading. Under this environment, students influenced by teachers and gradeorientation also focus their learning center on “superficial form of oral English"(Heng, 2020, p.11)[45]. In this case, the quality of content that students are conveying could be ignored, which may slow down the advance of thinking ability (Zhu, 2021)[46]. In other words, whether students are able to produce expressions with analysis, coding, judgement, deducing and reasoning in speaking may not garner much attention. Thereby, it could be the main reason that thinking skill in oral English of English majors are in a low level.

Currently, the fact is that students have low level in English critical thinking so that there is a question, that is, whether it is necessary for them to own thinking ability during learning oral English.

\subsection{What is the impact of cultivating thinking ability in the training of oral English?}

Thinking skill is of great importance and necessity for learning oral English, which can be seen in two aspects. First, from the perspective of national higher education, cultivation of this capacity is one of core objectives in Chinese higher education.

Outline of national medium and long term education reform and development plan

(2010-2020) confirm:

Education remains stress on ability, improves structure of knowledge, enriches social experience, and strengthens cultivation of ability. Education needs to advance students capacity on learning, practice, innovation. In addition, it should cultivate students to procure knowledge skill, life skill and to be a better person, which makes students actively adapt themselves to society.

The general provisions of the Higher Education Law of the People's Republic of

China stipulate that the task of higher education is to train senior professionals with

\section{innovative spirit and practical ability.}

From these two authentic documents, it can be seen that "ability", "practical, ability", "innovative spirit" are highly recommended. Innovation perhaps can create new things and make outdated things adapt to trend of society development (Yang \& Wang, 2018)[19]. Practical ability means the capacity to solve barriers in practical life. Practice is the muse of innovative spirit and it comes into life in practice, both of which needs thinking. Innovation is based on practice, so it needs considerations to limitation of current practice and possibility of improvement. Meanwhile, innovation is inspected in practice, which means that practice needs thinking to check whether innovation is appropriate. Therefore, it appears that the core of practical ability and innovative spirit may be thinking skill. In Sun's study (2011)[51], he highlights that "thinking skill is the premise of innovative spirit and practical ability" (p.51). Therefore, in the process of reform in higher education, cultivation of thinking skill is put on the high position. That is, it is necessary for teachers and learners to emphasize thinking skill in oral English teaching and learning (Sun, 2015)[49].

Second, in Wen and Zhou's studies (2006)[38], these studies find that from the perspective of relationship between thinking and language, the development of thinking has an impact on the level of oral English.

Wen and Zhou (2006)[38] suggests that "people build up concept through words; judge and deduce through sentences; form rational cognition through analysis of sensed phenomenon and finally formulate new knowledge system" (p.76). From this procedure, it seems to appear that level of language is necessary condition to ascend level of thinking and in turn, advance of thinking can boost up the language level. That is, during the teaching of oral English, teachers should recognize the importance of thinking ability and think about how to train thinking skill in oral English learning of students.

From these two findings, it could be seen that it is necessary for students to be equipped with thinking ability when learning oral English, but they seemingly lack this ability. Therefore, I wonder if DP and debate can bring some ideas. 


\subsection{What advantages does debate have in learning?}

Generally, debate enable students to learn in an active way. Zhang (2016)[20] shows that "debate can increase student's interest in learning” (p. 685). It appears that learners may be fond of taking part in discussions about attracting topic (Zhang, 2018)[50]. When encountering theme which draws their much attention, they perhaps are willing to share their own perspective or suggestion. In this case, they might be able to learn lessons actively. Besides attractive topic, Zhang (2018)[50] states that students own the agency in debate practice (p. 151). It seems like that conducting one debate requires students to do full preparation before class (Chen, 2021)[24], where they need to look for sufficient materials for supporting their statements and avoid being refuted by rivals on their own, which seems to be one of ways to self-learning. In class, instead of traditional form that teachers are the center in lecture, students become center (Chen, 2021)[24]. It takes most of the time for students to perform and show themselves. During the debate, they share their opinions and have reaction to rivals attacking in gaps of statements or evidence. Apart from agency, Zhang (2005)[47] expounds that "students feel satisfied and successful after performance” (p. 685). It appears that teachers may give them encouragement and give them positive comments, while classmates may give them applause according to their excellent performance. Therefore, it shows that students seem to be more willing to learn in debate class due to attractive topic, achievement of agency and self-success.

Apart from standing on the side of learning motivation, debate may also boost the critical thinking up (Liu \& Jin, 2012; Yan, 2018)[16][37]. The word of "critical" is originated from two roots in Greek, "kritikos" and "criterion". On the layer of cognition, critical thinking is to think based on suitable comment standard and make proper judgement, which can be appeared concretely in two facets (Sun, 2015)[49]. During preparation of debate, Zhang (2010)[48] shows that "the ability of recognizing, defining, excluding, understanding may be developed" (p. 107). When students are given a thesis statement, they might will figure out definition to some items through reading a variety of authentic papers and identify one which is more suitable to the statement, where they learn how to recognize related materials and how to find appropriate definition through their own understanding and excluding. In addition, Zhang (2010)[48] expounds that "debate can increase students capacity of deducing, explaining, supposing and reasoning” (p. 107). During forming causes and effects, learners are likely to give their own opinions through conclusion and offer sufficient evidence to decrease the possibility to be attacked. Meanwhile, they may need to suppose rivals thinking patterns to cover gaps, where training of deduction and supposition is conducted.
Overall, the findings show that through debate practice, it is likely for students to improve their critical thinking.

From these three findings, it can be seen that students' oral English training mainly focuses on forms, which seems to be embodied in vocabulary memory and grammar learning (Liao, 2020)[15]. However, it ignores ability training of information processing, text understanding, as well as deeper reasoning and analysis, such as ignorance of language connotation, which may be reflected in "language expression, social, cultural, life, history exercises and rational thinking” (Liao, 2020, p. 115)[15]. Meanwhile, Under the guidance of Outline of the National Medium-and Long-Term Education Reform and Development Plan (2010-2020), college English educators began to explore how to break through the limitations of traditional teaching mode and improve students' critical thinking ability. Experts put forward that in order to cultivate college students' English critical thinking ability, they should cultivate ability of "expounding, analyzing, evaluating, reasoning and explaining” (Zhang, 2021, p. 167)[23] in the cognitive process.

According to results of findings associated with debates' advantages, training of debate seems to advance thinking ability in an effective way. experts' consideration of thinking ability training is corresponded with training mode of debate. Through debate, students may procure the abilities of "recognizing, defining, excluding, understanding, deducing, explaining, supposing and reasoning” (Zhang, 2010, p. 107)[48], which seems to fit the above requirements of training thinking ability in oral English. Therefore, in designing activities of cultivating English critical thinking ability, teachers perhaps can take debate into consideration.

\subsection{What ability can students procure in class applying DP?}

In teaching and learning, DP can help students garner ability of meta-cognition. Niu (2021)[4] points out that students can procure meta-cognition ability in class employing DP theory which emphasizes duly reflection and effective instruction (p. 10). Machfauzia and Djohan (2019)[2] explains that "meta-cognition essentially means cognition about cognition; that is, it refers to second-order cognition: reflections about actions" ( $\mathrm{p}$. 458). On the side of monitoring, where the acquisition of meta-cognition might be achieved is that they may will question themselves whether they have fully absorbed learned knowledge and whether they are able to use what they learn in practice. In this case, meta-cognition might come into working. They perhaps self-monitor their learning effects. On the side of planning, training of metacognition may be demonstrated on plan setting ( $\mathrm{Li} \&$ Long, 2021)[17]. According to DP's requirement, learners need to make plans where there is an achievable aim and clarified steps. This point can be seen in the 
literature review above (Ericsson \& Pool, 2016, p.129)[1]. Therefore, in teaching, students seem to ascend their meta-cognitive ability through setting their unique plans based on the understanding of themselves. Besides, this ability might be acquired through self-adjustment. After a series of training in DP class, students might be judged by themselves, which means that they give themselves feedback in terms of the results in practice. Through comparing the ideal result and their current result, they may know their shortages and so make proper adjustments to their plan. In this way, they might perform better in the next practice. Overall, under the instruction of mental representative DP probably enables students to acquire meta-cognitive ability which is suitable to the principals of cognitive psychology (Yan, 2018)[37].

The findings show that by using DP as a training method during the lesson, students are likely to garner the ability of meta-cognition in that DP stress self-reflection when learners do not have specific guides (Ericsson \& Pool, 2016)[1]. In class, there is perhaps one teacher to teach a host of students. Therefore, in class guided by DP, students are likely to self-reflect their own performance through planning, monitoring and adjusting, during which meta-cognition is grown in their mind. Besides, according to theory of processing information, metacognitive strategy is an advanced level technique. It develops learning through planning, monitoring and adjusting to learning itself, which is corresponded with statement mentioned above. In Feng's study (2007)[29], the result shows that the relation between ability of metacognition and level of oral English is positive, which means that oral English level of students with higher meta-cognitive level is better than that of those with lower level (Feng \& Gong, 2007)[25].

Through analysis of these two groups, it appears that meta-cognition is the bridge to connect DP and oral English learning, which means that DP seemingly can be put into the practice of teaching oral English in that acquisition of meta-cognition in DP may ascend oral English to a higher level.

\section{CONCLUSION}

Overall, this paper is aimed to discover the links between DP, debate and oral English learning. Based on this objective, four questions are expounded and four findings are referred, that is, first, China oral English learning may lacks thinking training; second, thinking ability seems to be necessary for students to procure in university; third, debate probably can motivate students to learn and cultivate students' critical thinking; forth, DP might help students form meta-cognition in learning. This paper connects DP, and debate with oral English learning, which may give a future research idea about the improvement of oral English. Besides, due to limitation of this paper style, experimental research is another improvement in future study.

\section{AUTHORS' CONTRIBUTIONS}

The author expounded topic studied, designed research, performed research, analyzed data and wrote the paper.

\section{ACKNOWLEDGMENTS}

My deepest gratitude goes first and foremost to my supervisor, Jingjing Lin for her constant encouragement and guidance. She has walked me through all the stages of the writing of this thesis. Without her consistent and illuminating instruction, this thesis could not have reached its present form.

Second, I would like to express my heartful gratitude to Professor Chen and Professor Zhou, who assisted revision of translating relevant materials. I am also greatly indebted to the professors and teachers of Guangdong University of Foreign Study, who have been guiding me in the field of language teaching.

\section{REFERENCES}

[1] A. Ericsson, \& R. Pool. (2016). Peak:Secrets from the New Science of Expertise. China Machine Press.

[2] A. N. Machfauzia, \& Djohan. (2019). Intellectual Character of Metacognition: Student Thinking Strategies in Playing Music. ECTI-CON 2019, 458461.

[3] Acheson, K., Taylor, J., \& Luna, K. (2016). The Burnout Spiral: The Emotion Labor of Five Rural U.S. Foreign Language Teachers. The Modern Language Journal, 100(2), 522-537. https://doi.org/10.1111/modl.12333

[4] B. R. Niu. (2021). Ke yi lian yi: $\mathrm{Cu}$ jin zuo ye gai jin de yige shi jiao( $\langle$ Deliberate Practice $\rangle:$ A Perspective to Promote the Improvement of Homework.). Ji chu jiao yu ke cheng(Basic education curriculum.), 6, 915.

[5] Barbieri, B., Sulis, I., Porcu, M., \& Toland, M. D. (2019). Italian Teachers' Well-Being Within the High School Context: Evidence From a Large Scale Survey. Frontiers in Psychology, 10, 1926. https://doi.org/10.3389/fpsyg.2019.01926

[6] Bronkhorst, L.H., Meijer, P.C., Koster, B., \& Vermunt, J.D. (2014). Deliberate practice in teacher education. European Journal of Teacher Education, 1, 18-34.

[7] Combs, H, \& Bourne, S. (1994). The renaissance of educational debate: Results of a five-year study of the use of debate in business education. Journal on Excellence in College Teaching, 1(5), 57-67.

[8] D. Y. Xing, \& Bolden, B. (2019). Exploring Oral English Learning Motivation in Chinese International Students with Low Oral English 
Proficiency. Journal of International Students, 9(3), 834-855. https://doi.org/10.32674/jis.v9i3.749

[9] D’Souza, C. (2013). Debating: A catalyst to enhance learning skills and competencies. Education + Training, 55(6), 538-549. https://doi.org/10.1108/ET-10-2011-0097

[10] Ericsson, K.A., Krampe, R.T., \& Tesch-R mer,C. (1993). The role of deliberate practice in the acquisition of expert per formance. American Psychological Association, 3, 363-406.

[11] EricssonKA. (2014). Ex p e r t i s e. C u r r B i o l, 24(11), 508-510.

[12] F. Xie, W. Wang, Z. Z. Zhao, Ji, \& Yu. (2020). Ji yu ke yi lian xi li nian de bing li fen xi jiao xue zai ma zui ke zhu yuan yi shi gui pei zhong de ying yong (Application of case analysis teaching based on deliberate practice concept in the training of anesthesiology residents ). Xian dai yi yao wei sheng (Modern medicine and health.), 36(24), 4021-4023.

[13] Fauzan, U. (2016). Enhancing Speaking Ability of EFL Students through Debate and Peer Assessment. EFL Journal, 1(1), 49. https://doi.org/10.21462/eflj.v1i1.8

[14] Galton. (1872). On blood relationship. Proc. R. Soc., 20, 394-401.

[15] H. Liao. (2020). Ying yong xing ben ke gao xiao fei ying yu zhuan ye da xue sheng si bian neng li diao cha yan jiu(Study on the Thinking Ability of NonEnglish Majors in Application-oriented Universities.). Jiao yu jiao xue lun tan (EDUCATION AND TEACHING FORUM), 47, $115-116$.

[16] H. Liu, \& L. M. Jin. (2012). Ying yu bian lun yu da xue sheng pi pa xing si wei da zhan de shi zheng yan jiu(An Empirical Study on English Debate and the Development of College Students' Critical Thinking.). Wai yu yu wai yu jiao xue(Foreign language and foreign language teaching.), 5, 24-28.

[17] H. R. Li, \& L. L. Long. (2021). Yuan ren zhi ce lue zai gao zhong ying yu ting li jiao xue zhong de yun yong tan tao(On the application of metacognitive strategies in English listening teaching in senior high schools.). Ying yu Guang Chang(English Square), 11, 131-133.

[18] H. Y. Sheng. (2009). Shi jie guan gai nian tan jiu(Concept exploration of world outlook.). $\mathrm{Hu}$ bei han shou da xue xue bao(Journal of HUBEI Corresponden e University), 22(3), 109-110.

[19] H. Y. Yang, \& S. Q. Wang. (2018). Wen ke shuo shi yan jiu sheng ying yong yan jiu neng li yu chuang xin jing sheng de pei yang(Cultivation of applied research ability and innovative spirit of liberal arts postgraduates.). Jue ce $y u$ xin xi(Decision and information.), 1, 77-84.

[20] H. Y. Zhang. (2016). Ying yu bian lun ke dui xue sheng si bian neng li ying xiang de shi zheng yan jiu. Liao ning jing ji guan li gan bu xue yuan liang ning jing ji zhi ye ji shu xue yuan xue bao(Liaoning Economic Management Cadre College. Journal of Liaoning Economic Vocational and Technical College.), 5, 111-114+118.

[21] Hu, G. (2003). English language teaching in China: Regional differences and contributing factors. Journal of Multilingual \& Multicultural Development, 24(4), 290-318.

[22] J. Shi. (2017). Qiang hua da xue ying yu jiao xue zhong de pi pa xing si wei pei yang (Strengthening the cultivation of critical thinking in college English teaching.). Hai wai ying yu(Overseas English), 11, 69-70.

[23] J. Zhang. (2021). Xu lun shi yu xia da xue sheng ying yu si bian neng li pei yang yan jiu(On the Cultivation of College Students' English Critical Thinking Ability from the Perspective of Continuation.). $\mathrm{Ke}$ jiao wen hui(The Science Education Article Collects), 1, 166-168.

[24] L. S. Chen. (2021). Bian lun shi jiao xue zai da xue ying yu zhuan ye ting li ke tang de jiao xue tan jiu yu ying yong yi gao ji ying yu shi ting shuo ke cheng wei li(Exploration and Application of Debate Teaching in Listening Class for College English Majors_-Taking 《Advanced English Listening and Speaking 》 as an example.). Ke jiao wen hui(The Science Education Article Collects), 5, 186188.

[25] L. Y. Feng, \& Z. Gong. (2007). Yuan ren zhi yu ying yu kou yu xue xi de xiang guan yan jiu(A study on metacognition and oral English learning.). Wai yu jie(Foreign languages community), 2, 58-64.

[26] Lantolf,J. (2006). Sociocultural theory and L2: State of the art. Studies in Second Language Acquisition, 28, 67-109.

[27] Lantolf,J. (2000a). Introducing sociocultural theory. Oxford University Press.

[28] Lantolf,J. (2000b). Second language learning as a mediated process. Language Teaching, 33, 79-96.

[29] Lantolf,J. (2000c). Sociocultural Theory and second language learning. Oxford University Press.

[30] Li. (2020). Li tan yi ying yu bian lun wei zai ti de kou yu ke zai gao zhong xiao ben ke cheng zhong de 
kai fa(On the development of oral English class based on English debate in school-based curriculum of senior high school.). Hai wai ying yu(Overseas English), 11, 15-17.

[31] Li, Z. (2021). Teacher Well-Being in EFL/ESL Classrooms. Frontiers in Psychology, 12, 732412. https://doi.org/10.3389/fpsyg.2021.732412

[32] Moeller,T. (1985). "Using classroom debates in teaching developmental psychology”. Teaching of Psychology, 4(12), 207-209.

[33] Ortega,L. (2011). SLA after the social turn: Where cognitivism and its alternatives stand. In D. Atkinson (Ed.). Alternative approaches to second language acquisition, 167-180.

[34] P. Freire. (1970). Pedagogy of the Oppressed. The Seabury Press.

https://doi.org/10.1016/j.system.2006.05.001

[35] Q. F. Wen. (1999). Kou yu jiao xue yu si bian neng li de pei yang. Guo wai wai yu jiao xue(Foreign language teaching abroad), 2, 1-4.

[36] Q. Guan, L. Xue, \& T. T. Lv. (2015). Jian yi he ke yi xu lian yu zhong guo da xue sheng ying yu cheng jiu de guan xi. Zhong guo te shu jiao yu(Chinese Journal of Special Education), 14(12), 78-82.

[37] Q. Yan. (2018). Ying yu bian lun yu da xue sheng pi pa xing si wei fa zhan de shi zheng yan jiu(An Empirical Study on English Debate and the Development of College Students' Critical Thinking.). Zhang jia kou zhi ye ji shu xue yuan xue bao(Journal of Zhangjiakou Vocational and Technical College), 31(4), 31-33.

[38] Q.F.Wen, \& F. Zhou. (2006). Ping shu wai yu zhuan ye xue sheng si wei neng li de fa zhan(Comment on the development of foreign language majors' thinking ability.). Wai yu jiao xue (Foreign Language Teaching), 5, 76-80.

[39] R. Feldman. (2004). Pu tong xin li xue (Understanding Psychology). People's Telecon Publishing House.

[40] S. S. Liu. (2020). Ke yi lian xi zai di er ke tang de yun yong dui ti gao fa yu fa yin de you xiao xing yan jiu__Y Y zhong guo xue sheng wei li(Study on the Effectiveness of Deliberate Practice in the Second Classroom to Improve French PronunciationTaking Chinese students as an example.). Chang jiang cong kan (Changjiang series), 22(35), 37-38.

[41] Sauer, C. G., Newman, L. R., \& Leichtner, A. M. (2018). Training in Endoscopy:Coaching,Deliberate Practice, and Reflection. Journal of Pediatric Gastroenterology and Nutrition.
[42] Sawir, E., Marginson, S., Forbes-Mewett, H., Nyland, C., \& Ramia, G. (2012). International student security and English language proficiency. Journal of Studies in International Education, 16, 434-454.

[43] T. S. Kuhn. (1970). The Structure of Scientific Revolutions. University of Chikago Press.

[44] Vygotsky, L.S. (1978). Mind in Society: The Development of Higher Psychological Process. Harvard University Press.

[45] X. Heng. (2020). Da xue ying yu jiao xue zhong xue sheng pi pan xing si wei pei yang ce lue tan jiu(A Probe into the Strategies of Cultivating Students' Critical Thinking in College English Teaching.). Xian dai ying yu(Modern English), 8, 10-12.

[46] X. N. Zhu. (2021). 《Hu lian wang+》 bei jing xia de da xue ying yu jiao xue zhong si wei neng li de pei yang(Cultivation of Thinking Ability in College English Teaching under the Background of 《internet plus》.). Hai wai ying yu(Overseas English), 6, 164-165.

[47] X. S. Zhang. (2005). Ke tang yanjiang bian lun dui da xue ying yu xue xi de cu jin zuo yong(The Promoting Effect of Classroom Debate on College English Learning.). Hua bei mei tan yi xue yuan xue bao(Journal of North China Coal Medical College), 7(5), 685-686.

[48] Y. Q. Zhang. (2010). Ying yu bian lun yu ying yu zhuan ye xue sheng si wei neng li de pei yang yi ying yu bian lun gui ze wei zhi dao si xiang(Debate and the Cultivation of English Majors' Thinking Ability_Guided by English Debate Rules.). Guang dong wai yu wai mao da xue xue bao(JOURNAL OF GUANGDONG UNIVERSITY OF FOREIGN STUDIES), 21(6), 105-108.

[49] Y. Z. Sun. (2015). Wai yu jiao yu yu si bian neng li pei yang(Foreign language education and cultivation of critical thinking ability.). Zhong guo wai yu (Chinese Foreign Language), 12(2), 1+23.

[50] Z. W. Zhang. (2018). Da xue ying yu ke tang bian lun huo dong de quan liu cheng guan li mo shi yan $\mathrm{jiu}$ (Research on the whole process management mode of college English classroom debate activities.). Da xue jiao yu(University Education), $07,26-29+48$

[51] Z. Z. Sun. (2011). Tu chu si bian neng li pei yang, jiang ying yu zhuan ye jiao xue gai ge yin xiang shen ru(Emphasizing the cultivation of critical thinking ability and deepening the teaching reform of English majors.). Zhong guo wai yu(Chinese Foreign Language), 8(03), 49-58. 